ص ص ص[V-00]

أثر أسواق الأوراق المالية العربية في النمو الاقتصادي

\author{
دينا أحمد عمر

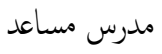 \\ المعهد التقني- نينوى مدرس
}

Dina_amor333@yahoo.com

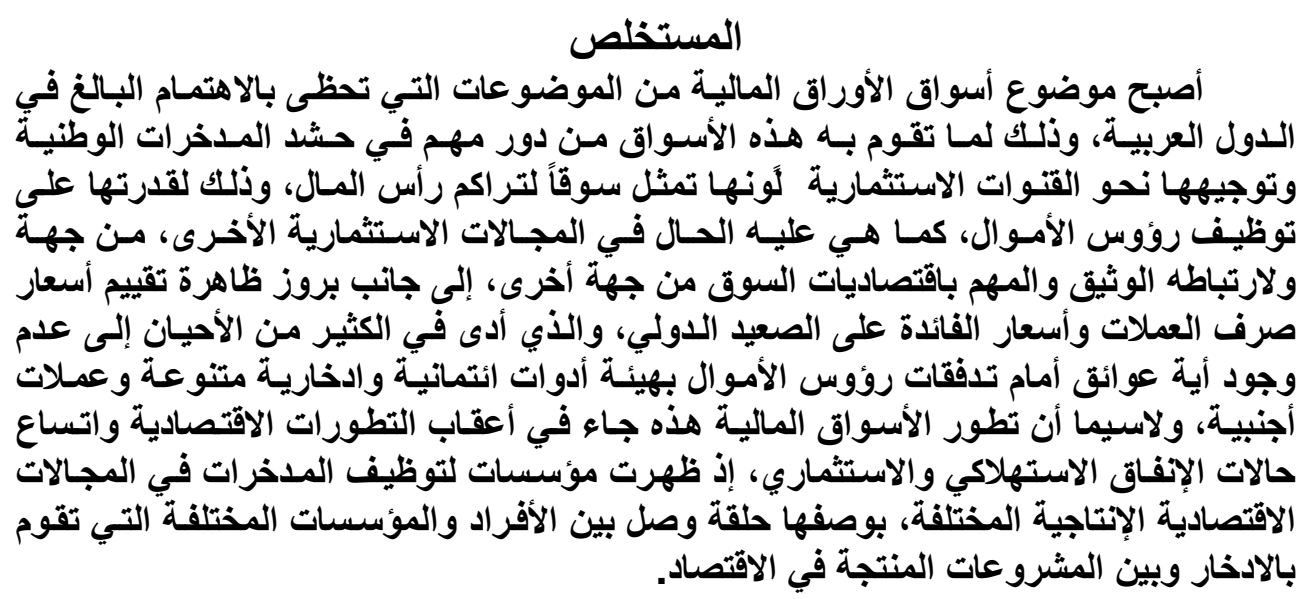

\title{
The Effect of Arab Stock Markets in Economic Growth
}

\author{
Dina A. Omar \\ Assistant Lecturer \\ Technical Institution - Mosul
}

\begin{abstract}
Stock markets became very essential subject in Arab countries. It has a vital role in aggregating and channeling national saving and directing them to Arab investment channels. These markets represent an area of accumulating capital as they are able to validate capitals on one hand, and for their strong and important relation with the market economies on the other. In addition to the emergence of exchange rate valuation and interest rate prices on the international level. They often lead to the removing of the barriers of capital flow in the form of various credit and saving instruments as well as to the foreign currency. The development of financial markets has almost followed specially the

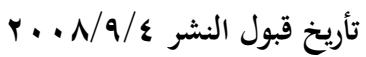

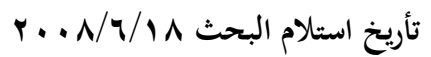




\section{عمر [04]}

economic growth and the consuming expenditure and investment expenditure. The emergence of institutions played a role in employing the savings in the economic and productive areas. They are however the connection between individuals and various institutions which save on the one hand and the productive projects in the economy on the other.

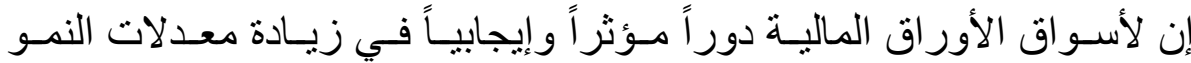

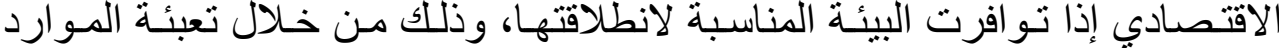

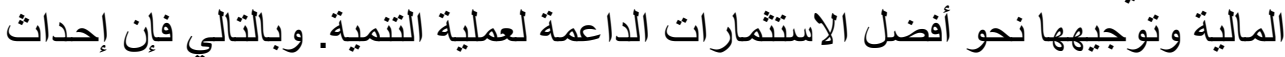

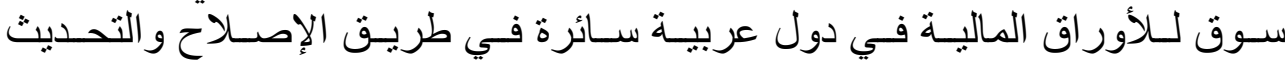

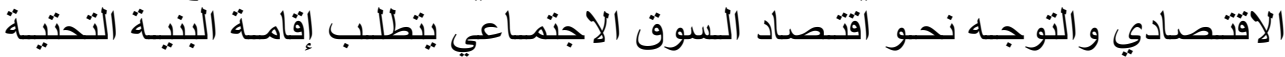

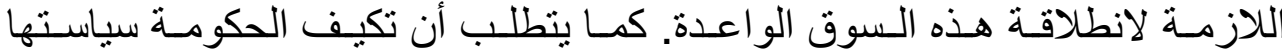

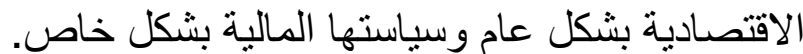

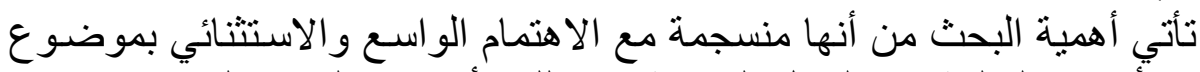

أهمية البحث

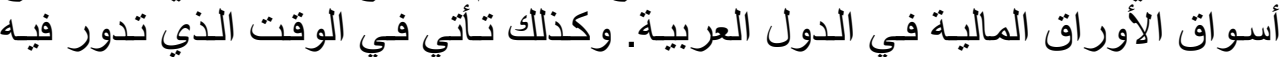

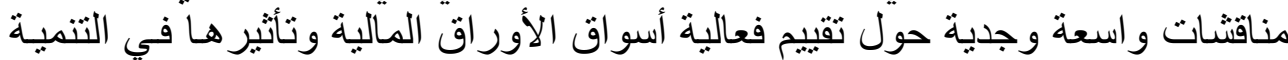
الاقتصادية للاول العربية.

مشكلة البحث تتلخص مشكلة البحث بعدم تو افر البيئة المناسبة لأسواق الأوراق المالية في

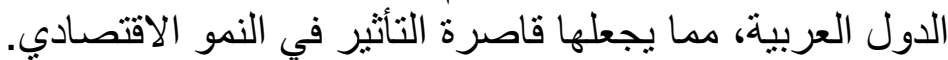
هدف البحث الوقوف على دور أسواق الأور اق المالية العربيـة في تفعيل النمو الاقتصـادي

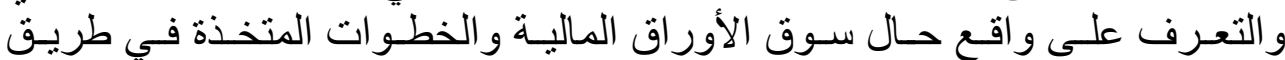

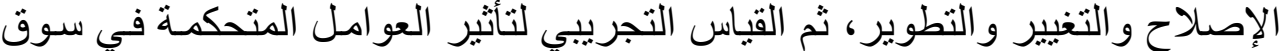
الأوراق المالية على النمو الاقتصادي.

إن سـوق الأوراق الماليـة العربيـة و على الر غم مـن تطور هـا مـاتز ال قاصـرة فرضية البحث التأثير في النمو الاقتصادي. 


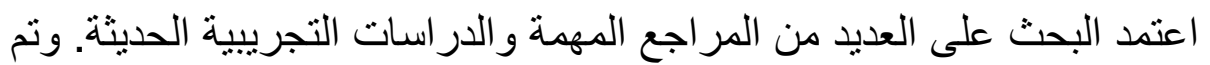

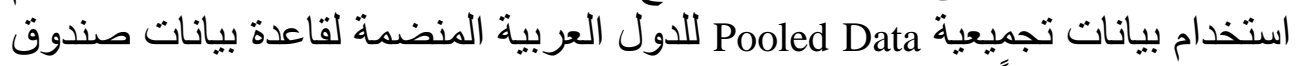

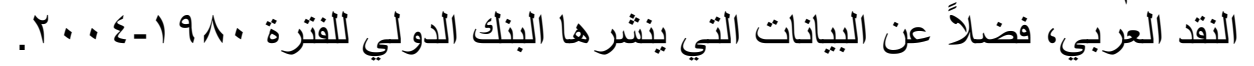

Financial Markets

الإطار النظري للبحث

السوق هو المكان التي يتم فيها التعامل بالأور اق المالية التية من أسهر وسندات بيعاً

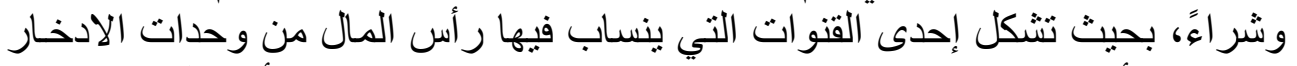

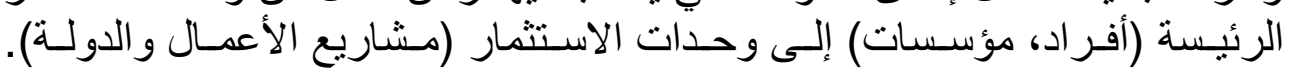

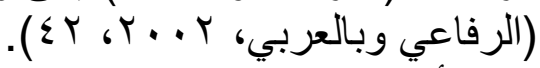

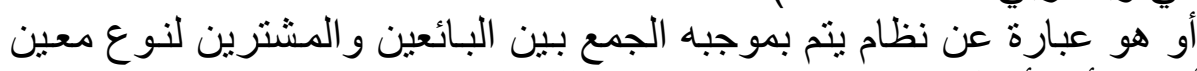

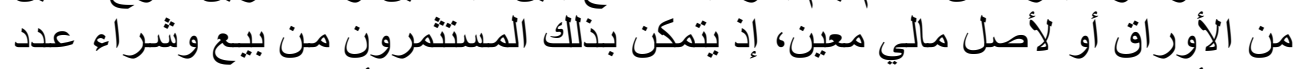

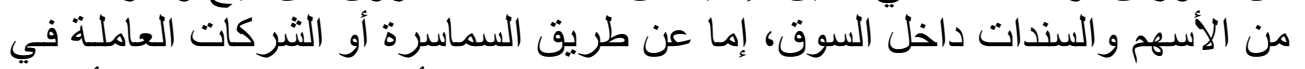

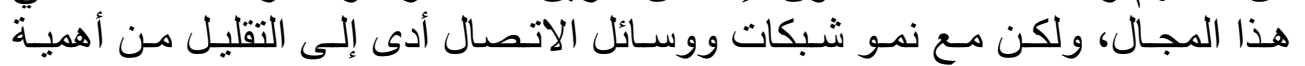

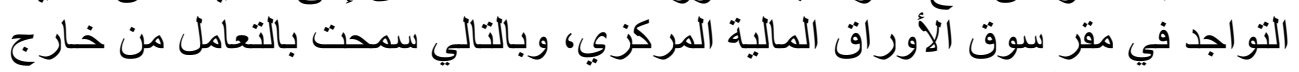

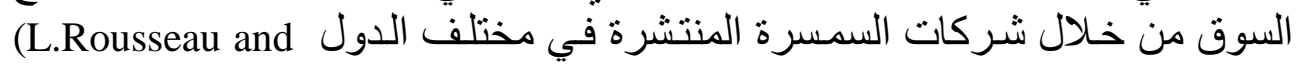
.Wachtel, 2005,2) وتعدد أسواق الأوراق المالية أحد نوعين من أنواع الأسواق الماليـة والمكونـــ من:

Money Market

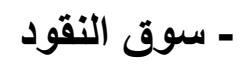

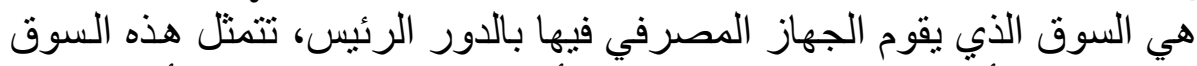

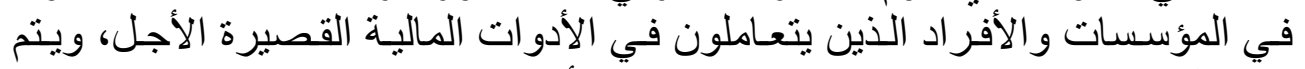

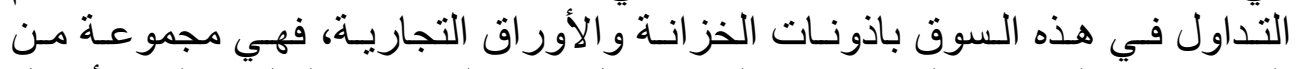

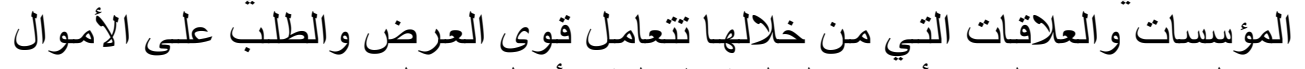

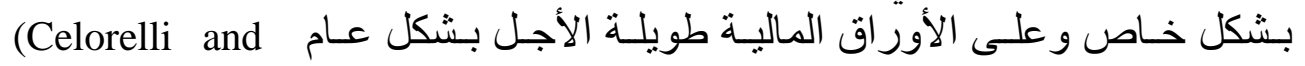
.Gambera,1999,7)

\section{Capital Market} - سوق رأس المال (الأوراق المالية)

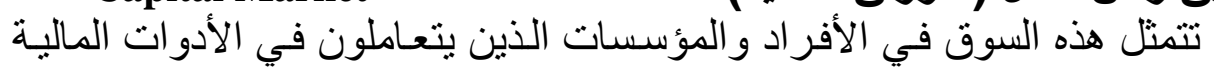

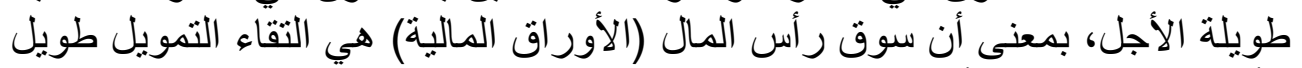

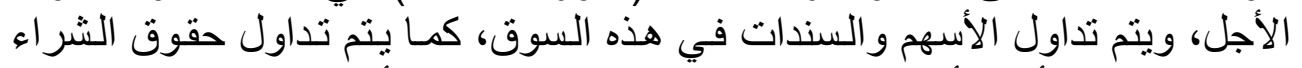

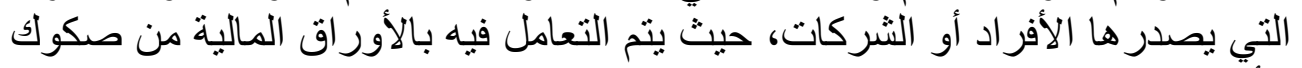

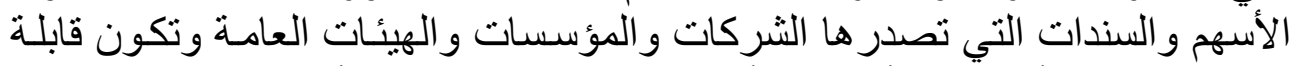

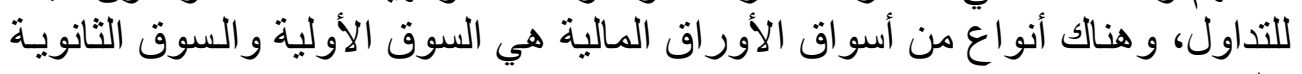

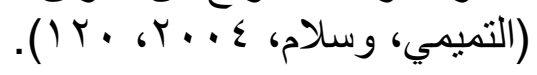




$$
\begin{aligned}
& \text { ثانياً- أنواع أسواق الأوراق المالية }
\end{aligned}
$$

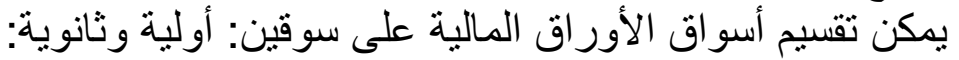

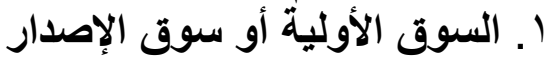

Primary Market

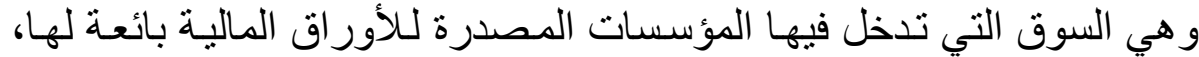

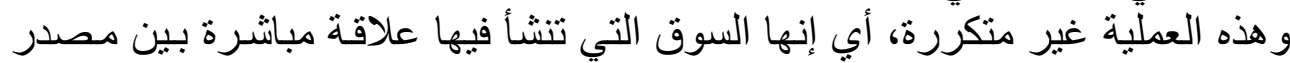

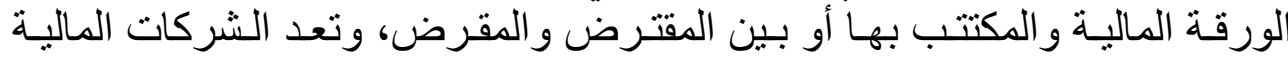

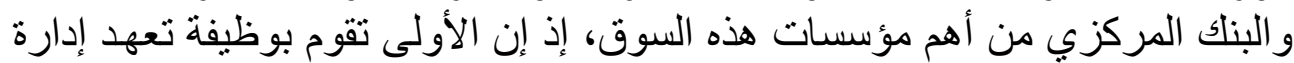

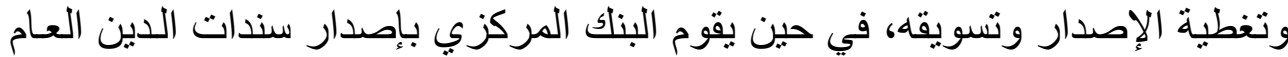

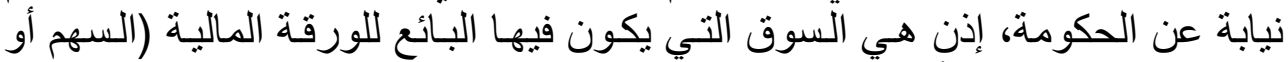
السند) هو مصدر ها الأصلي (Eatwell and Taylor, 1998, 40).

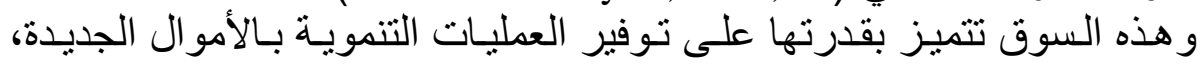

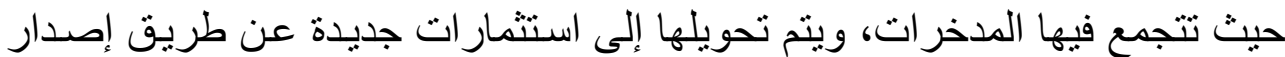

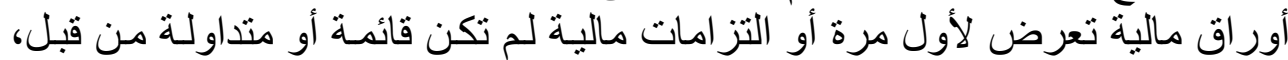

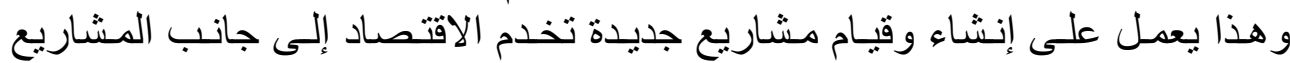

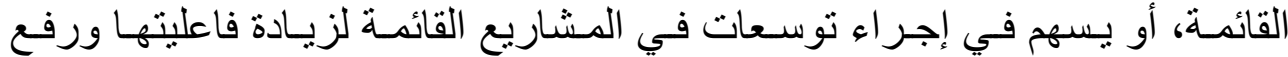

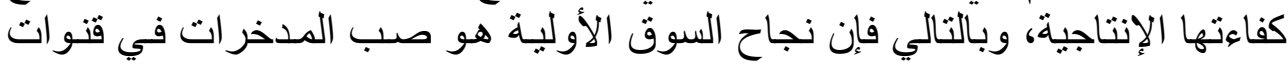

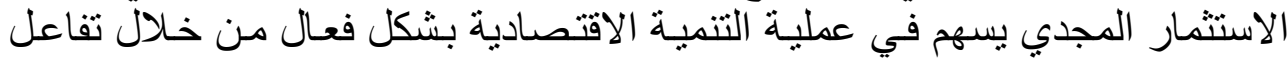

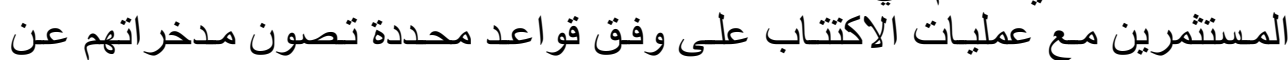

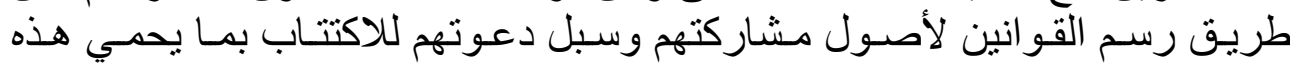

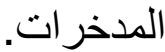

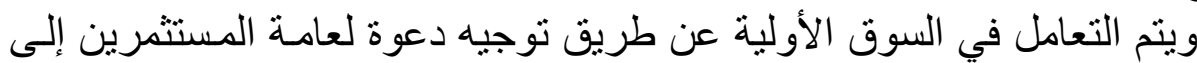

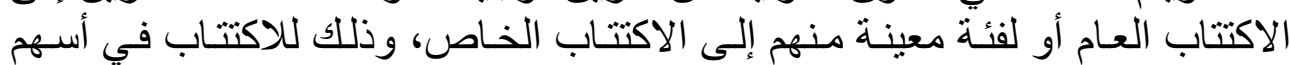

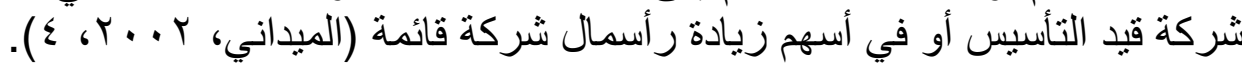

\section{Secondary Market}

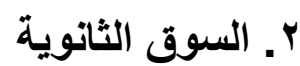

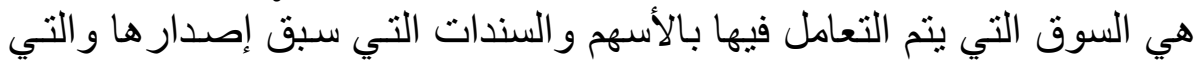

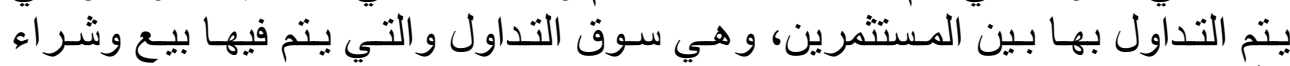

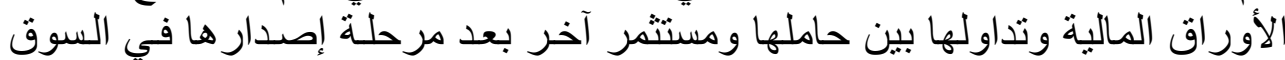

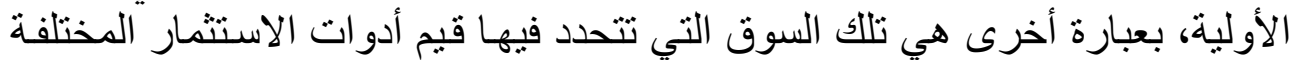

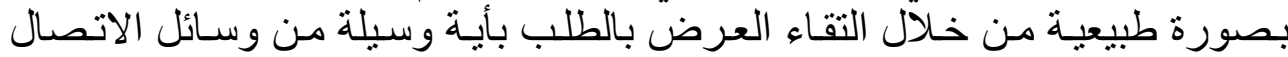

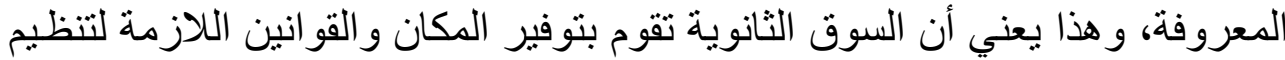

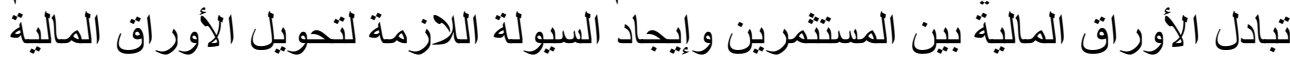

$$
\begin{aligned}
& \text { إلى نقد (Andritzky, 2007, 15). } \\
& \text { وتقسم السوق الثانوية على أربعة أسواق: }
\end{aligned}
$$




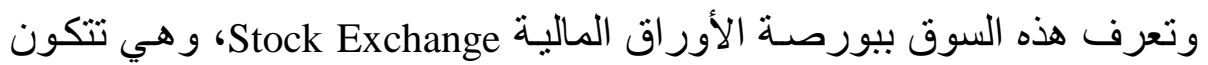

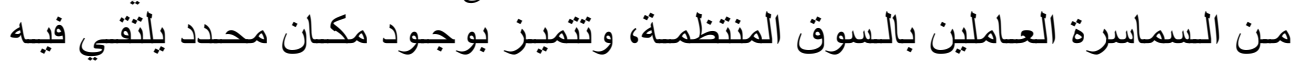

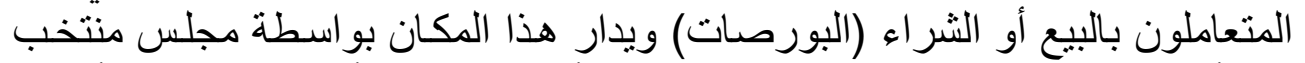

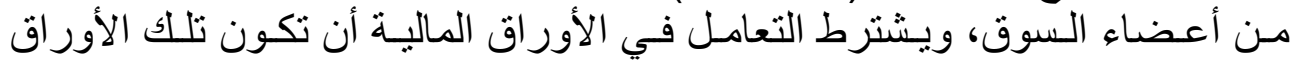

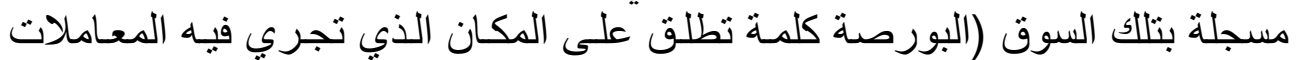

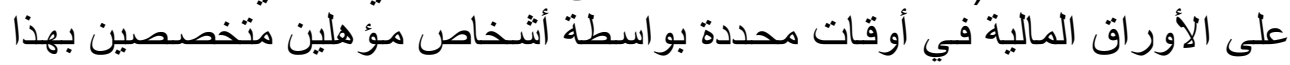

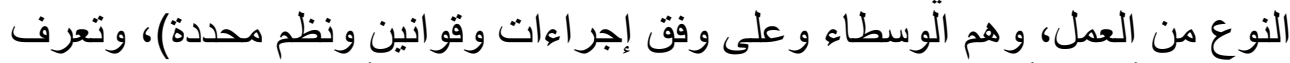

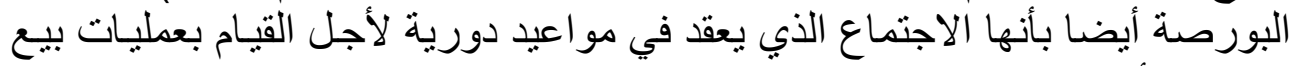

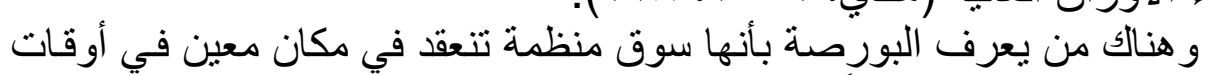

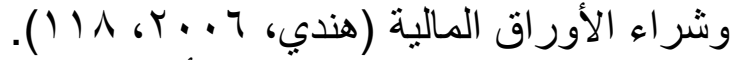

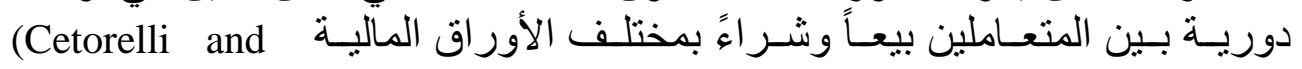
.Gambera, 1999, 11)

Organized Quasi Auction

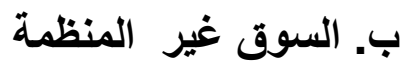

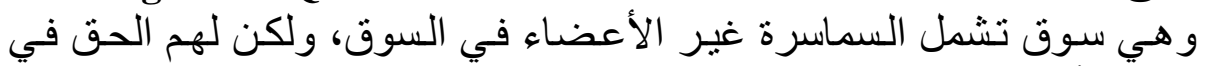

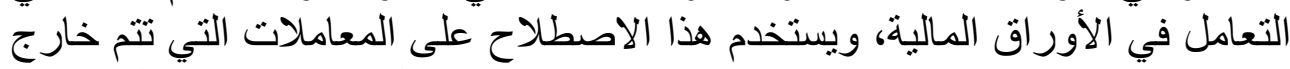

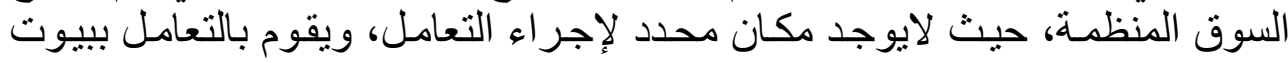

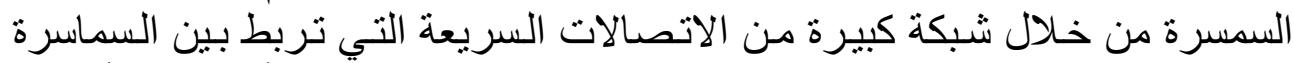

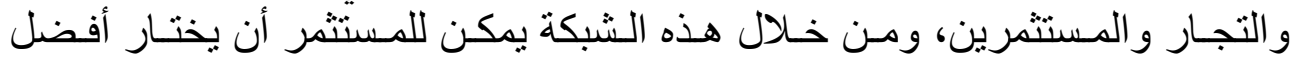

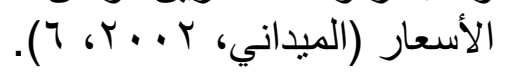

Over-The Counter

جـ. سوق ثالثة أو السوق الموازية

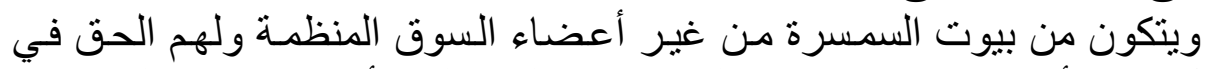

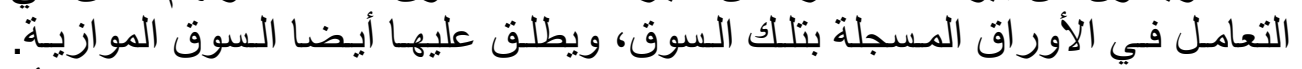

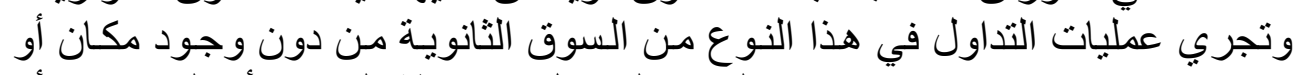

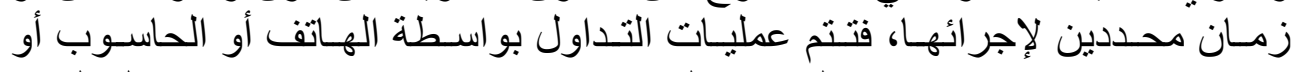

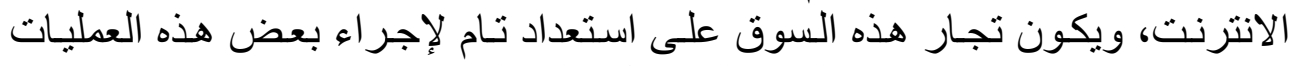

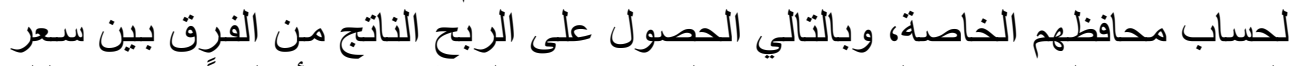

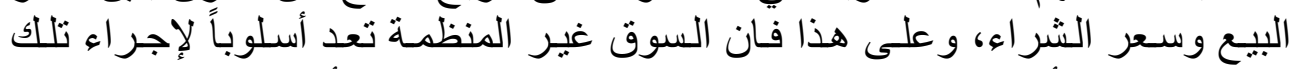

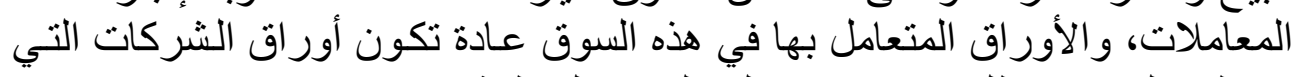

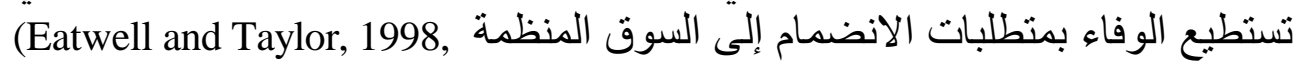

Private Market Or Direct Market د. السوق المباشرة أو الخاصة 
السوق الرابعة هي التي يتم التعامل فيها مباثرة بين الشركات الكبرى والتي التي التئي

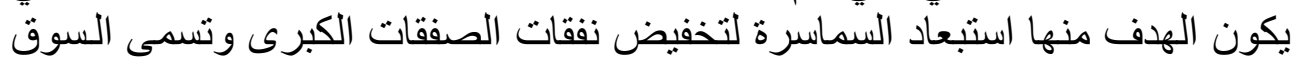
الاحتكارية (Hussein, 2006, 18).

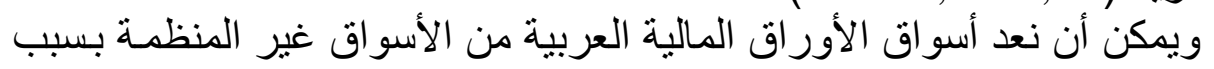

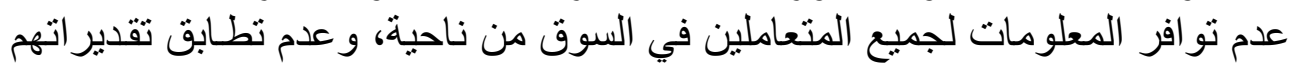

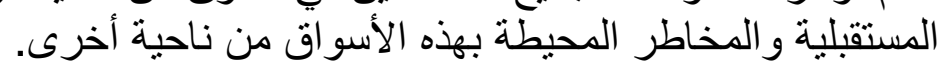

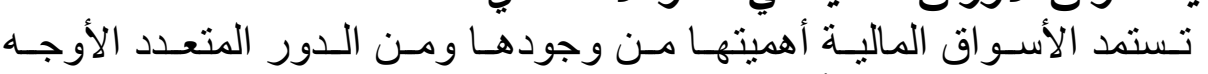
ـ أهمية أسواق الأوراق المالية في النمو الاقتصادي

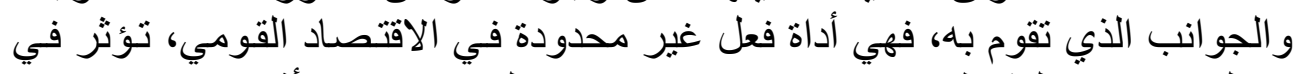

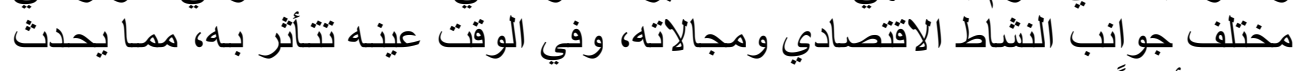

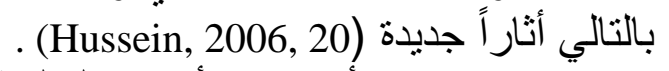

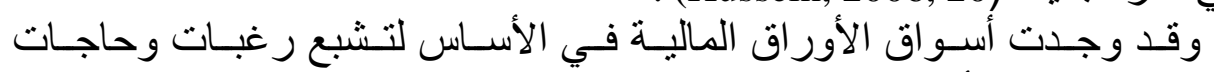

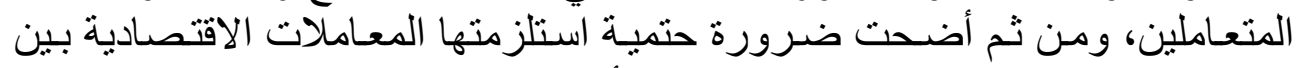

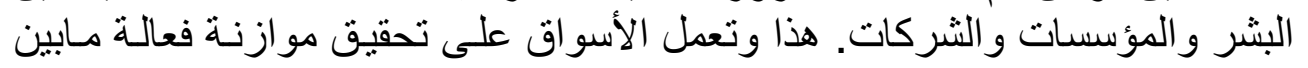

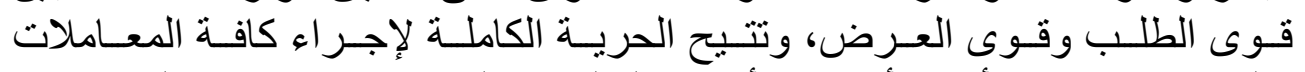

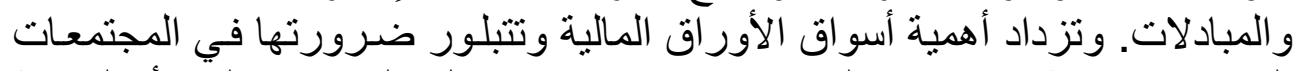

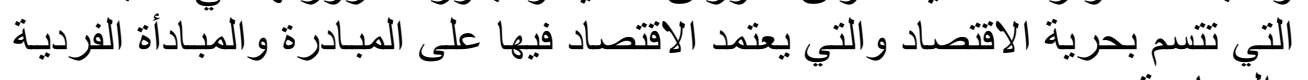
والجماعية (Lownsend and Ueda, 2005).

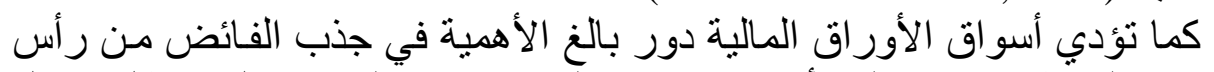

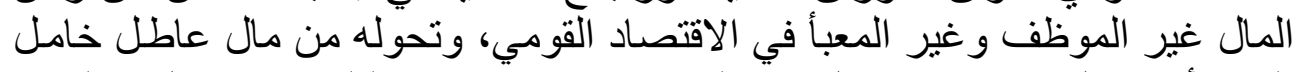

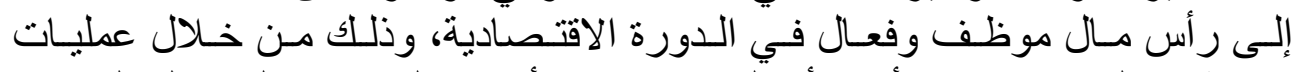

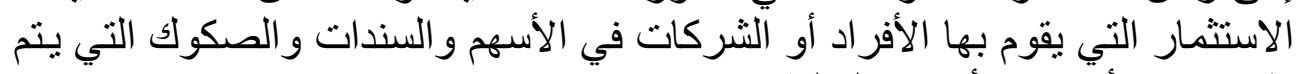

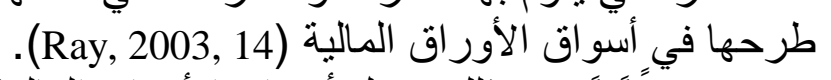

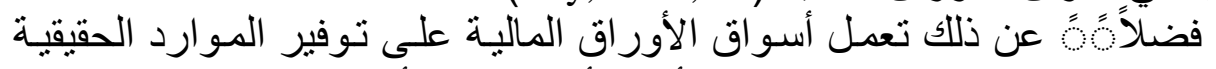

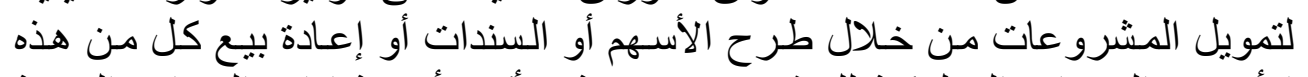

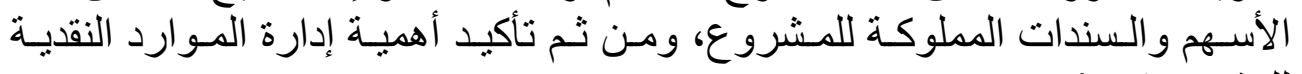

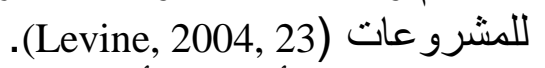
كما توفر أسواق الأوراق المالية قنوات ومداخيل التيل سليمة أمسام الأفراد و لاسيما

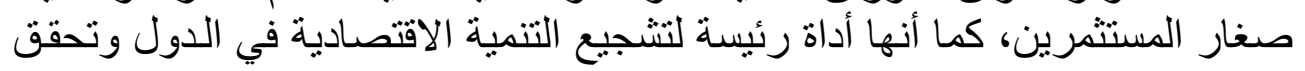

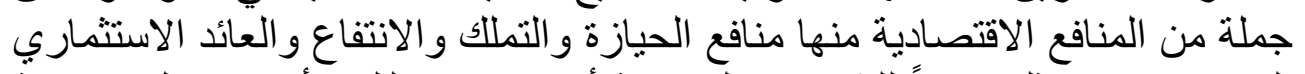

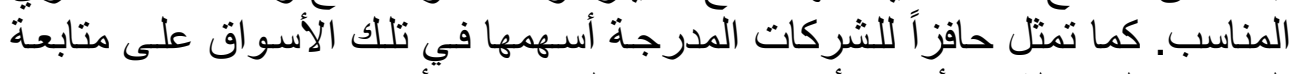

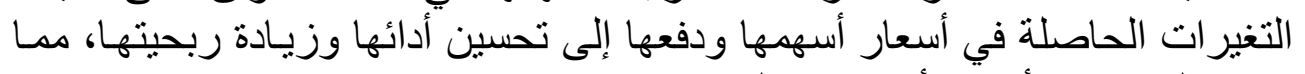

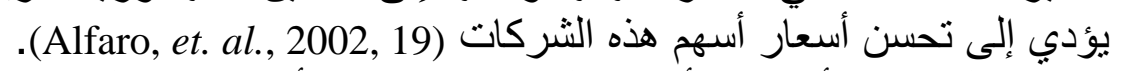
وكلما كانت أسواق الأور اق المالية فعالة كانت أكثر قدرة على العى تحقيق رسالتها

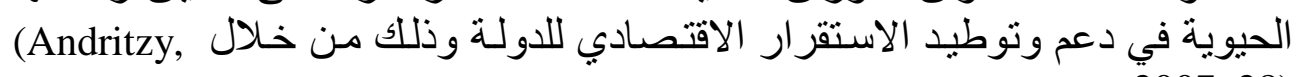
2007, 28) 


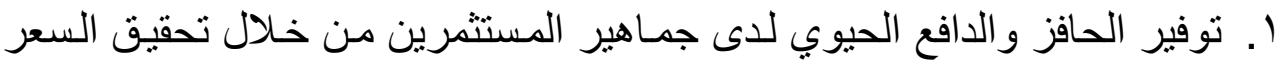

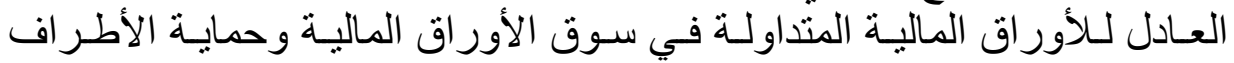

r. القدرة على توفير وإعادة تدوير كم مناسب من الأموال لتحقيق السيولة اللازمـة لبحتمع، ودعم الاستثمار ات ذات ذات الآجال المختلفة.

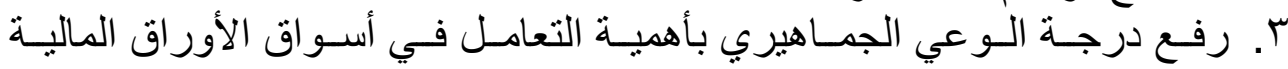

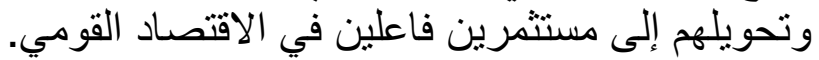

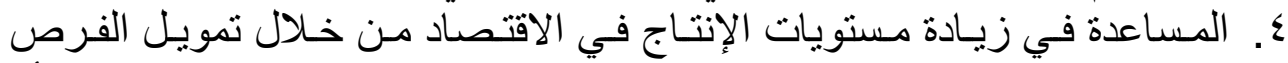

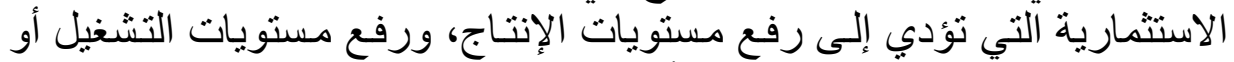
التوظيف، وبالتالي تحقيق مستويات أفضل للإخول سواء الاء على المستوى الفردي أو المستوى القومي.

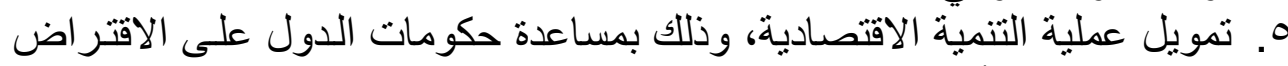

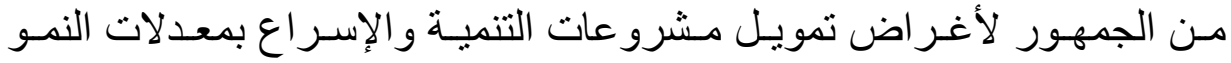

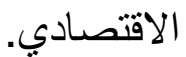

\section{ـ الاراسات التجريبية السابقة}

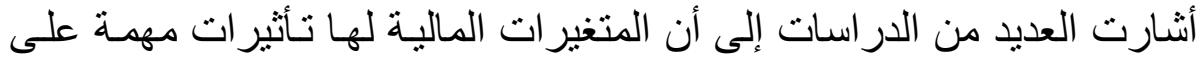

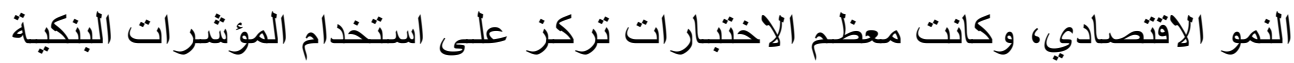

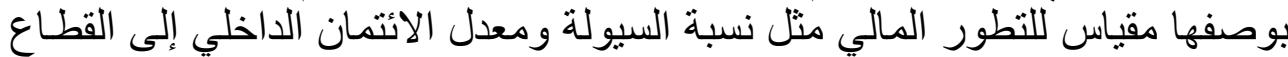

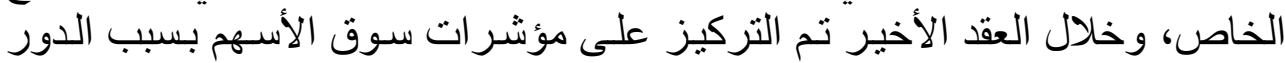

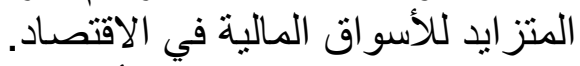

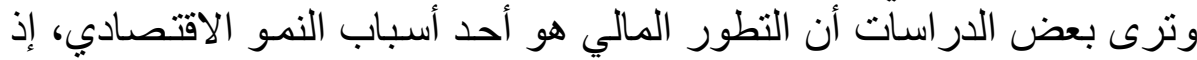

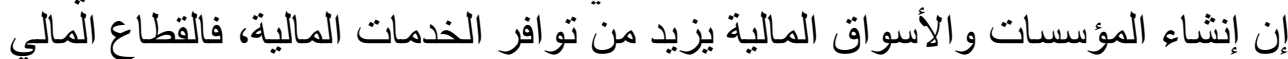

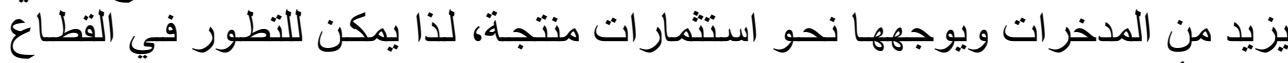
المالي أن يحث النمو الاقتصادي.

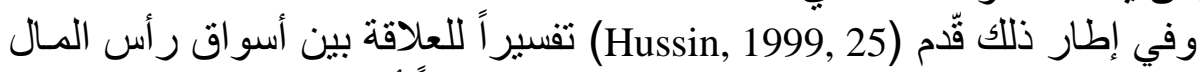

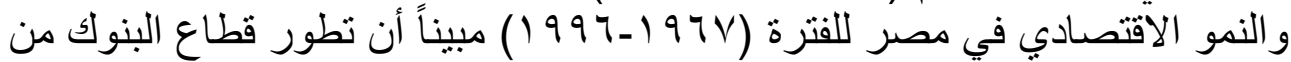

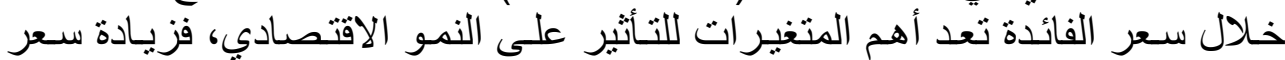

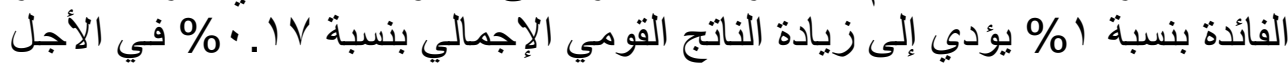

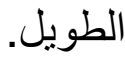

ويثير (Ahmad, 2004, 17) في بحثه إلى نتائج الدراسـة التجريبية في ماليزيـا

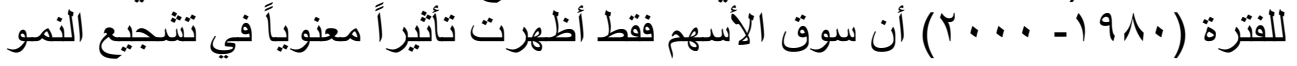

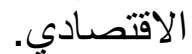
وفي در اسة لـ (Fecht, et. al., 2005, 32) تبين أن مخاطر أسو اق رأس المـال

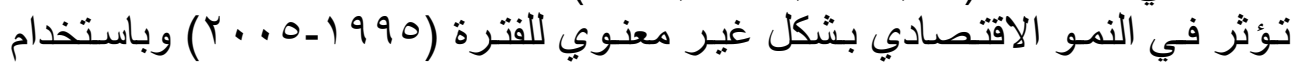
طريقة المربعات الصغرى الاعتيادية. 


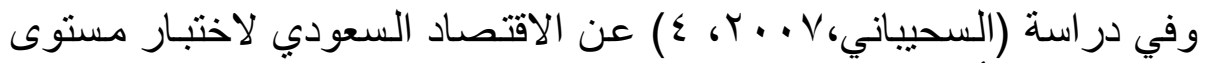

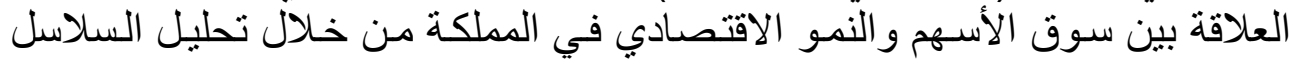

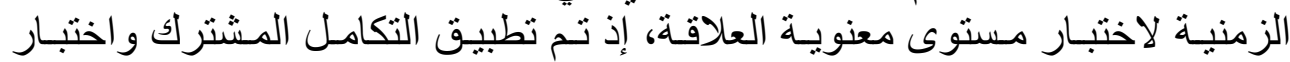

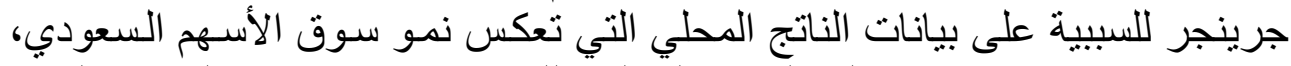

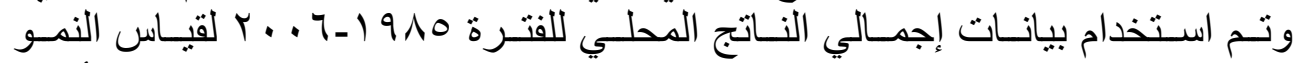

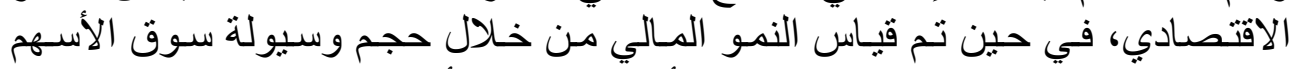

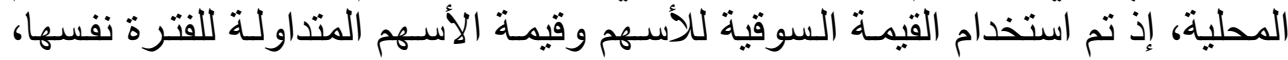

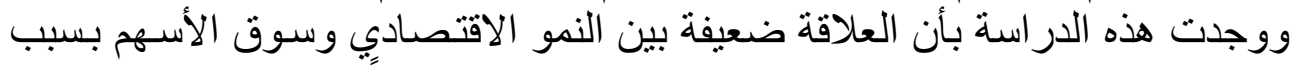

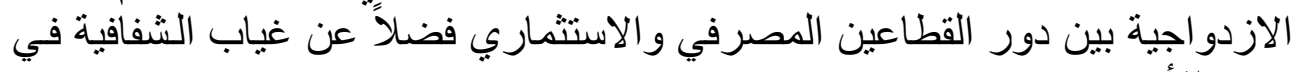

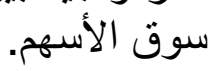

\section{ـ أنـــوذج لقيـاس العوامـل المتحكمـة فـي أسـواق الأوراق الماليـة علـى النمـو}

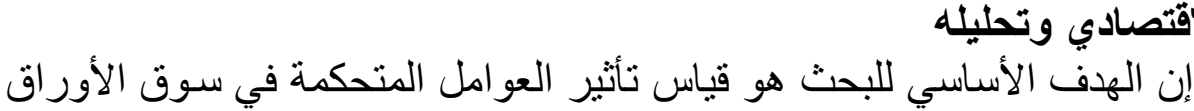

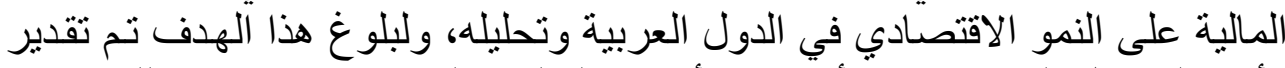

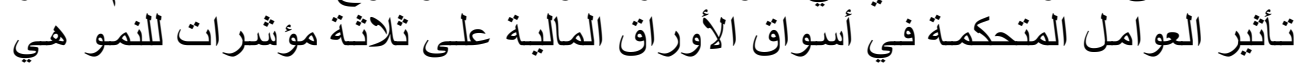

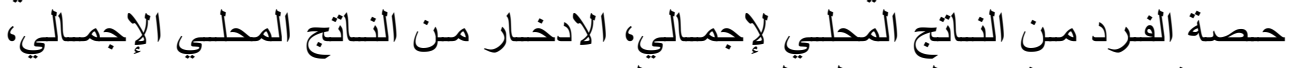
و الاستثمار كنسبة من الناتج المحلي الإجمالي.

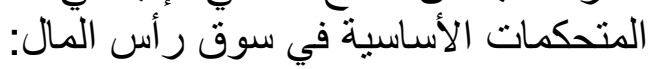

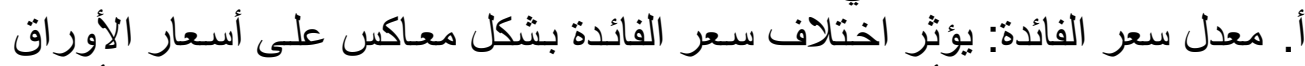

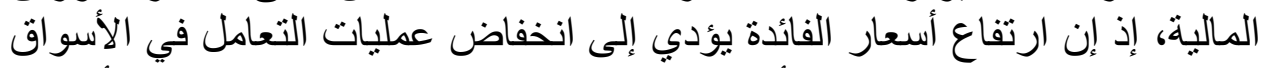

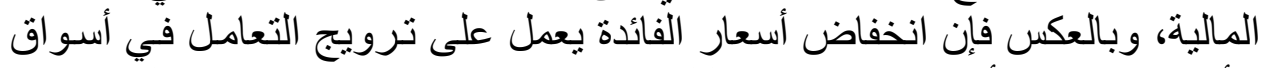

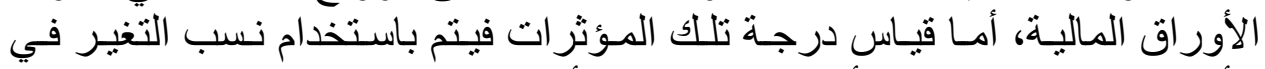
الأصول و الخصوم التي تتأثر بتلك التغير التير ات أو التذبذبات.

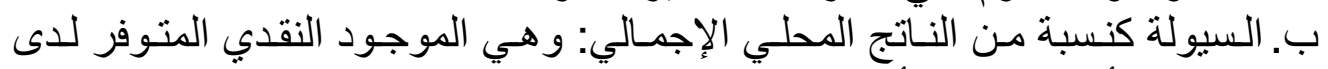

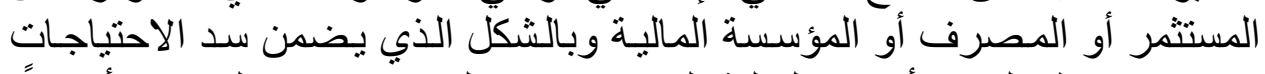

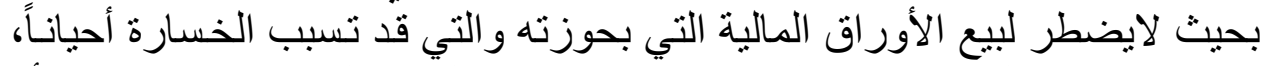

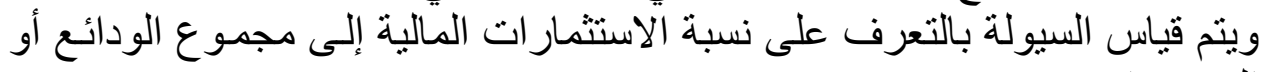

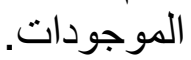
جـ. معدل الائتمان الداخلي إلى القطاع الخـاص كنسبة من النـاتج المحلي الإجمالي:

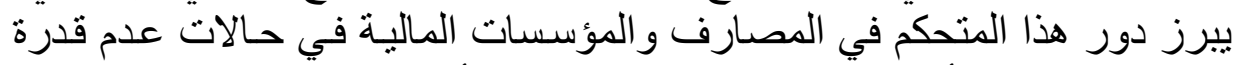

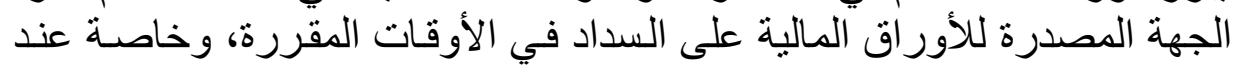

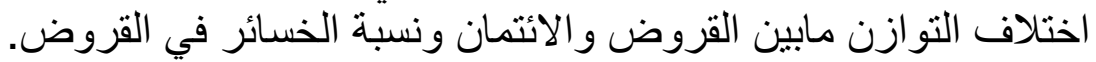

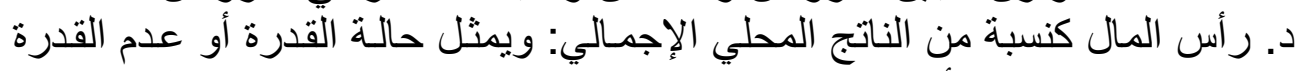

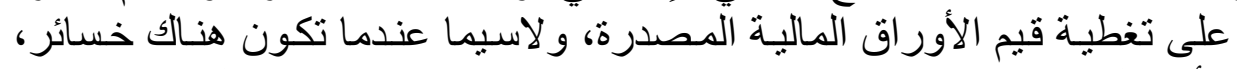

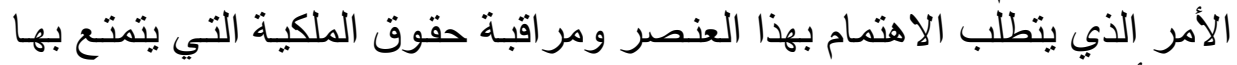


وتم قياس تأثير العوامل المتحكمة في أسواق رأس المال على النمو الاقتصادي

$$
\begin{array}{r}
\mathrm{GDP}=\alpha+\mathrm{C}+\mathrm{L}+\mathrm{i}+\mathrm{E} \\
\mathrm{S}=\alpha+\mathrm{C}+\mathrm{L}+\mathrm{i}+\mathrm{E} \\
\mathrm{I}=\alpha+\mathrm{C}+\mathrm{L}+i+\mathrm{E}
\end{array}
$$

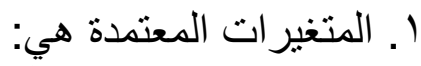

GDP : حصة الفرد من الناتج المحلي الإجمالي. I : الادخار كنسبة من الناتج المحلي الإجمالي. S r l الاستثمار كنسبة من الناتج المحلي الإجمالي. I الإلي.

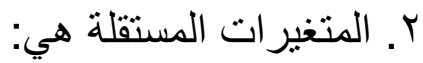

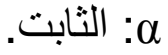
C L L السيولة كنسبة من الناتج المحلي الإجمالي. الإلي.

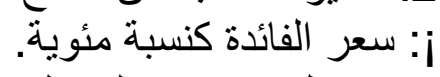

E : معدل الائتــان الداخلي إلـى القطـاع الخـاص كنسبة مـن النـاتج المحلي

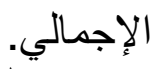

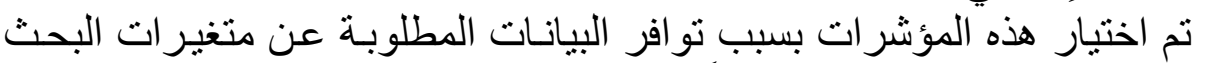

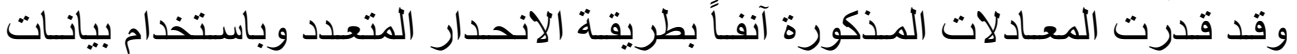

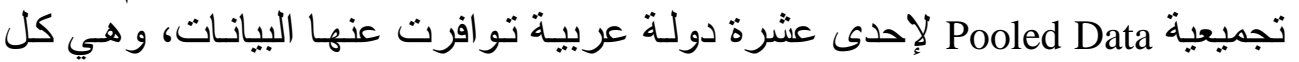

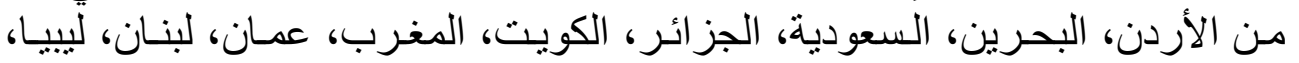

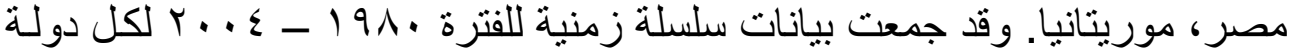

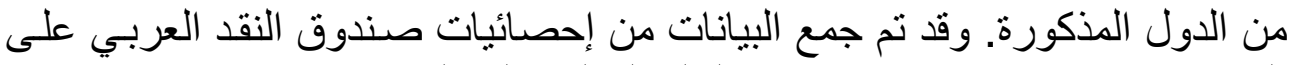

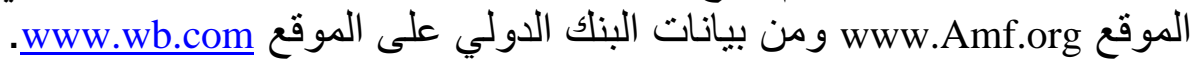

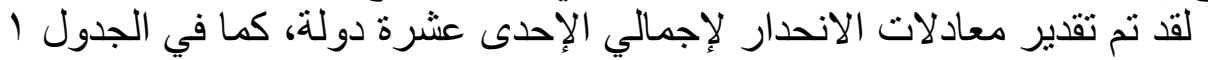

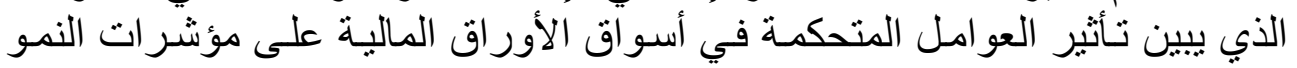
الاقتصادي المعتمدة في البحث.

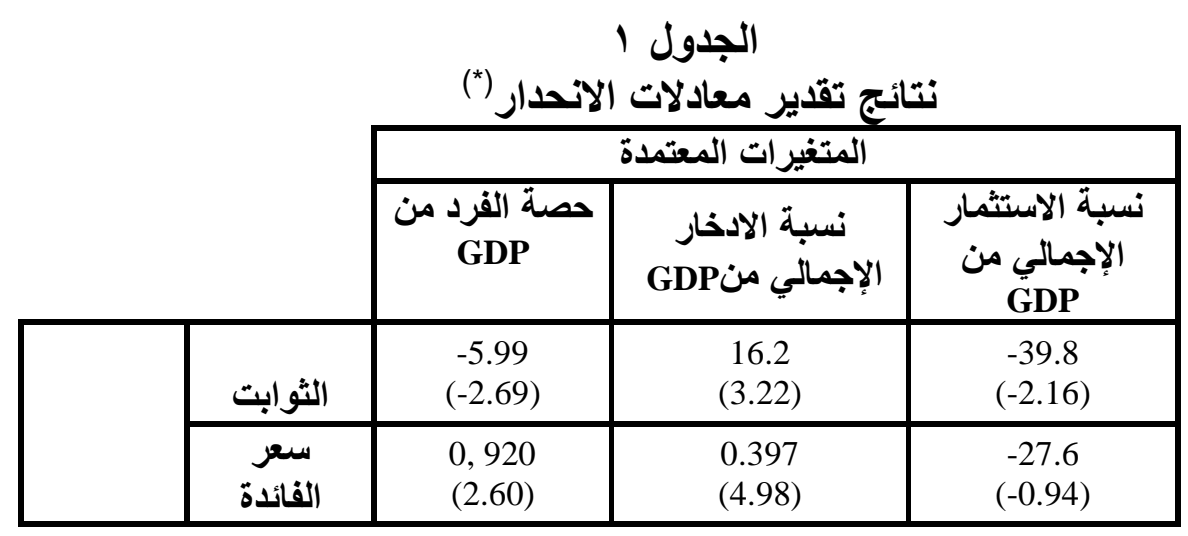




\begin{tabular}{|c|c|c|c|c|}
\hline \multirow[t]{3}{*}{ التفسيرية } & $\begin{array}{c}\text { كنسبة السيولة من } \\
\text { GDP } \\
\text { Gنبة }\end{array}$ & $\begin{array}{l}0.109 \\
(1.61)\end{array}$ & $\begin{array}{l}-0.487 \\
(-7.14)\end{array}$ & $\begin{array}{c}27.3 \\
(3.09)\end{array}$ \\
\hline & $\begin{array}{c}\text { كنسبة من الانتمان } \\
\text { GDP }\end{array}$ & $\begin{array}{l}0.128 \\
(4.52)\end{array}$ & $\begin{array}{l}0.188 \\
(2.95)\end{array}$ & $\begin{array}{c}-10.1 \\
(-0.43)\end{array}$ \\
\hline & كنسبة من أسال & $\begin{array}{l}0.191 \\
(1.52)\end{array}$ & $\begin{array}{l}0.662 \\
(0.22)\end{array}$ & $\begin{array}{c}189 \\
(1.80)\end{array}$ \\
\hline & $\mathbf{R}^{2}$ & $59.1 \%$ & $86.9 \%$ & $77.2 \%$ \\
\hline & DW & 0.89 & 0.62 & 1.76 \\
\hline
\end{tabular}

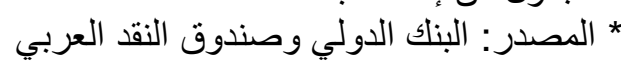

\begin{tabular}{|c|c|c|c|}
\hline & & \multicolumn{2}{|c|}{ يظهر من الجدول ا الآتي: } \\
\hline \multicolumn{4}{|c|}{ نتائج التحليل وتفسيرل ها } \\
\hline الأسباب & التحليل & مؤشرات النمو & أسواق رأس المال في \\
\hline \multirow{2}{*}{ 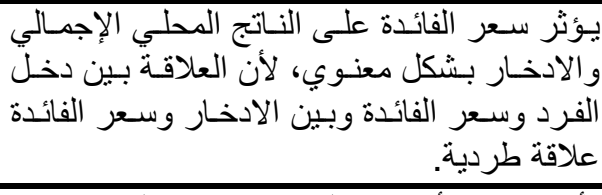 } & 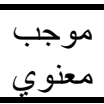 & GDP & أـ سئوية الفائـدة كنـسبة \\
\hline & 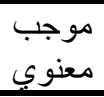 & S & \\
\hline 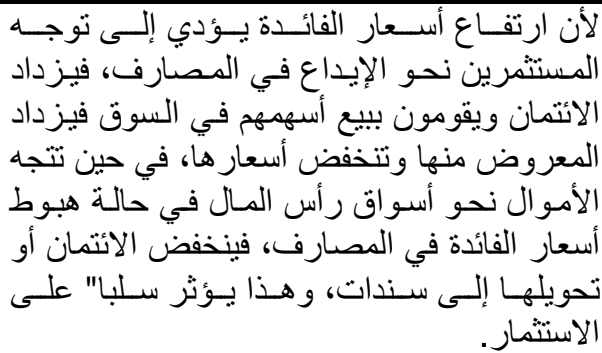 & 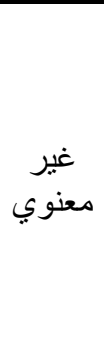 & I & \\
\hline 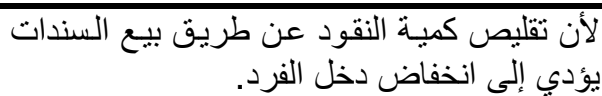 & 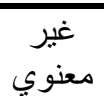 & GDP & \multirow{3}{*}{ 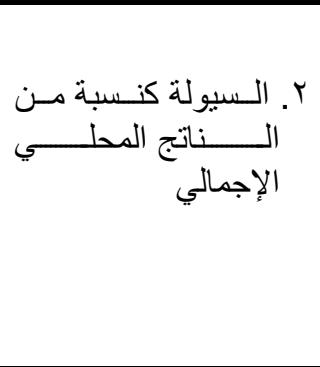 } \\
\hline 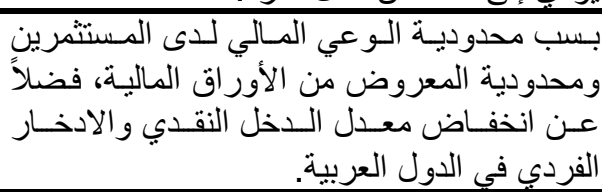 & 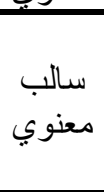 & $S$ & \\
\hline لأن زيادة السيولة تؤدي إلى زيادة الاستثمار. & 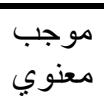 & I & \\
\hline 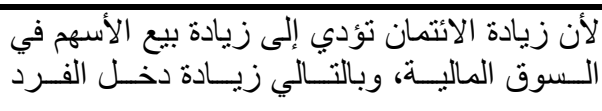 & معنوي & GDP & 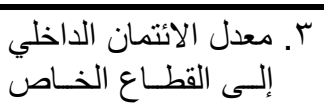 \\
\hline
\end{tabular}




\begin{tabular}{|c|c|c|c|}
\hline الأسباب & التحليل & مؤشرات النمو & أسواق رأس المال المتحمة في \\
\hline ومدخر اته. & 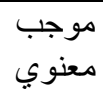 & $S$ & \multirow[t]{2}{*}{ 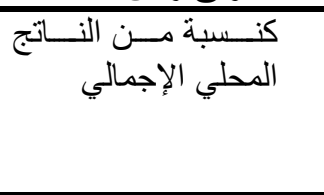 } \\
\hline على الاستثمار ات المحلثمان لدي المصارف يؤثر سلبا" & 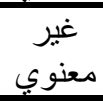 & I & \\
\hline لالآن رؤوس في الأمو ال قد تلجهـ إلى مشاريع أخرى & 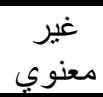 & GDP & \multirow{3}{*}{ 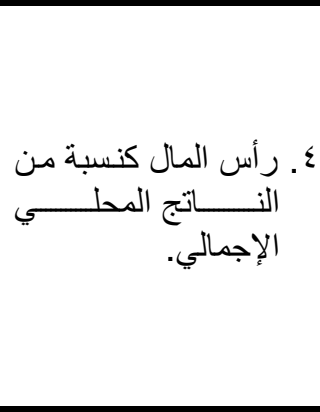 } \\
\hline 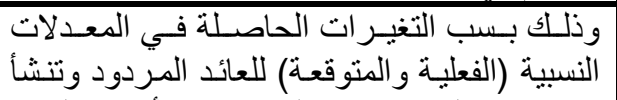 & مغنوي & $S$ & \\
\hline 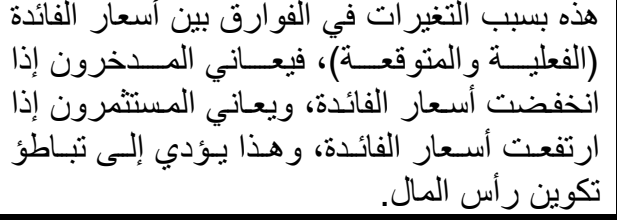 & 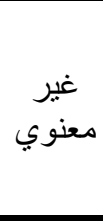 & I & \\
\hline
\end{tabular}

يمكن تفسير نتائج العلاقة الضعيفة بين النمو الاقتصادي وسوق الأوراق المالية

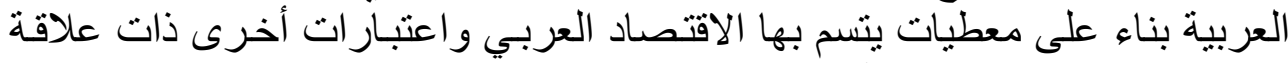
بالنظام المالي على النحو الآتي:

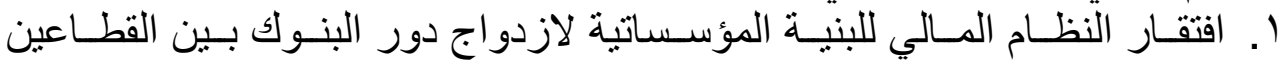

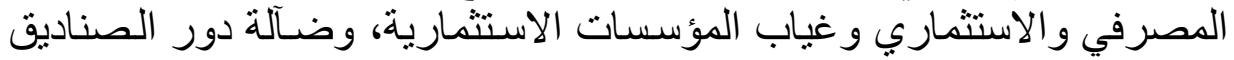

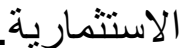
r. ضـفف كفاءة تخصيص وتوزيـع أعمـال الشركات المساهمة على القطاعـات

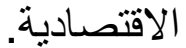

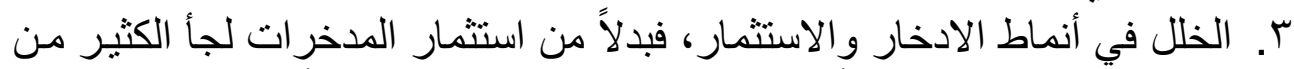

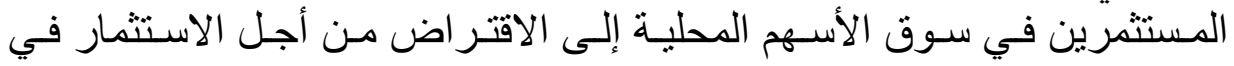

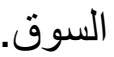
ع. القدرة المحدودة لسوق الأور اق الماليـة على خلق معلومـات للمستثمرين عن النشاط (غياب الثنفافية).

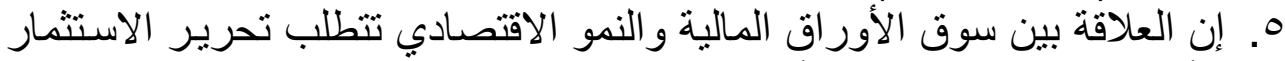

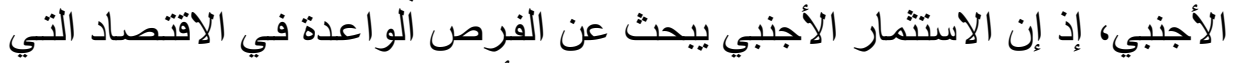

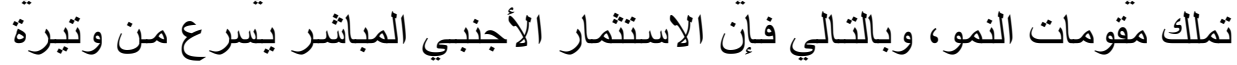

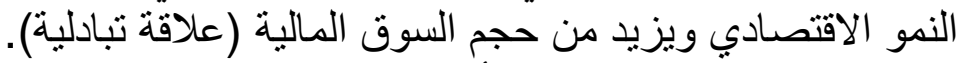

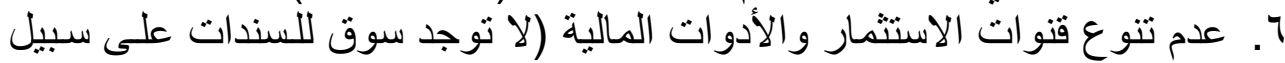

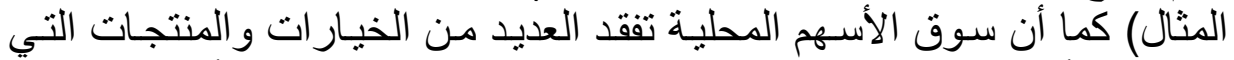

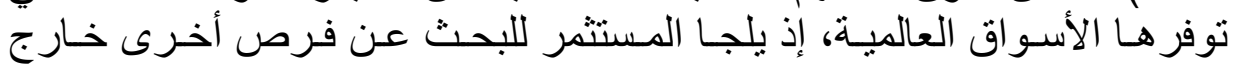

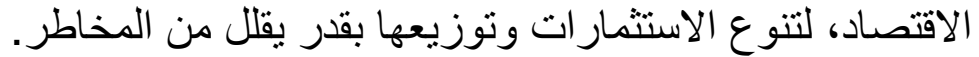


التوصيات

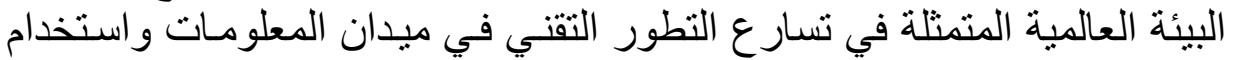

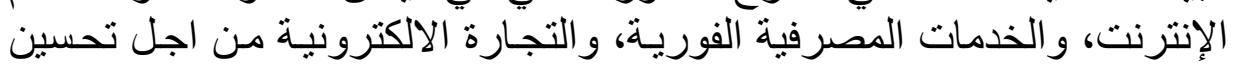

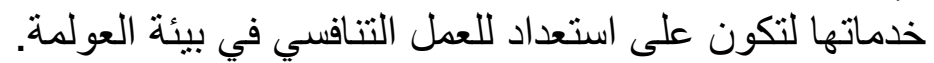

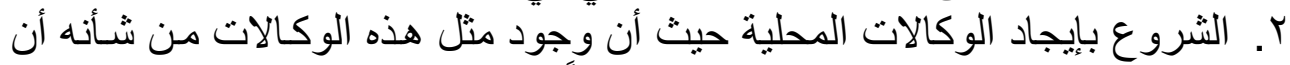

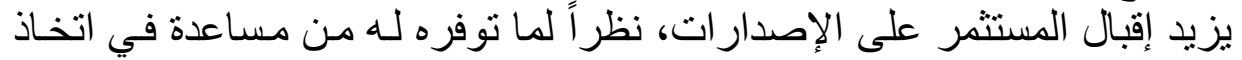
القرار ات الاستثمارية السليمة.

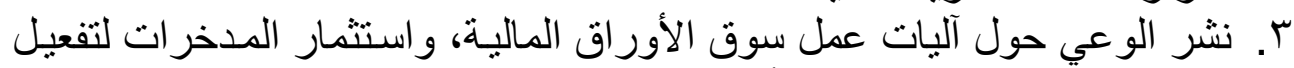

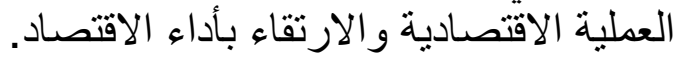

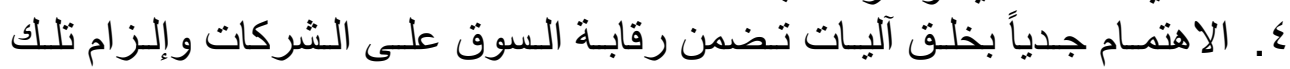

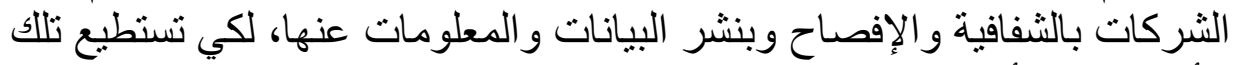

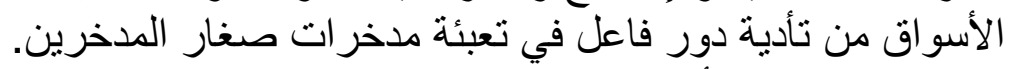

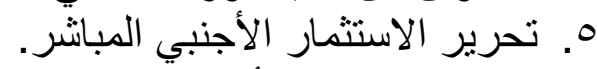

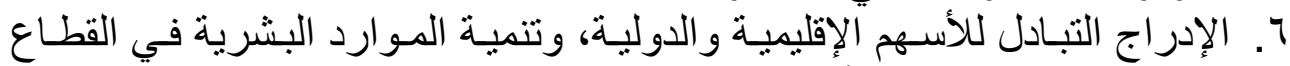

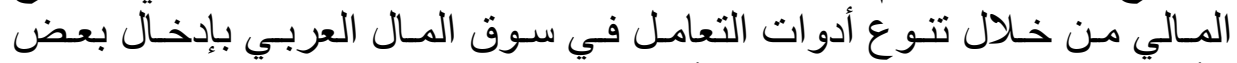

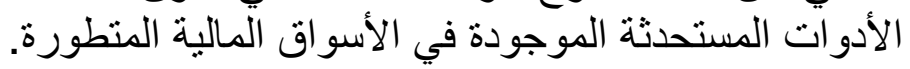

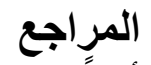

أولاً المراجع اجع باللغة العربية

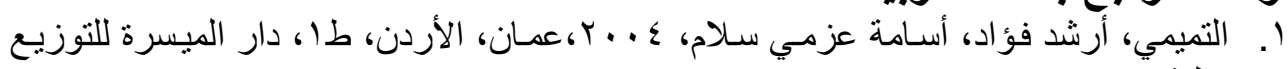
و النشر.

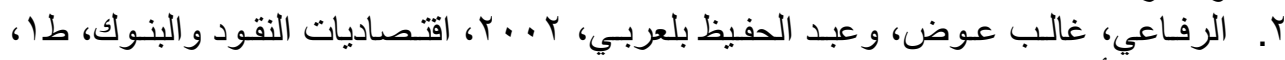

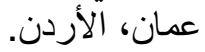

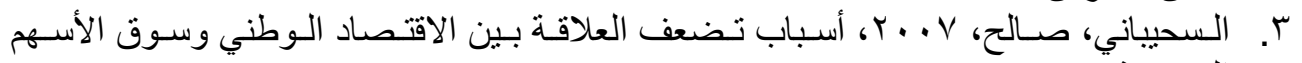

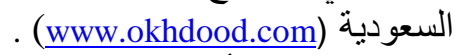

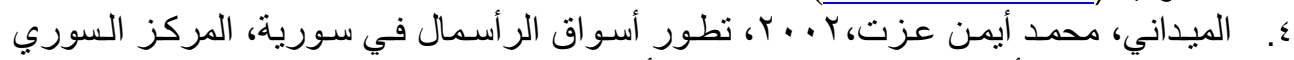

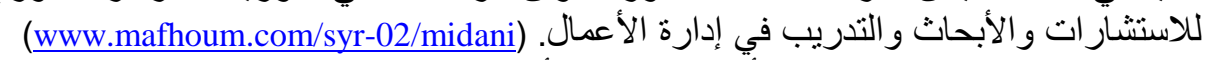

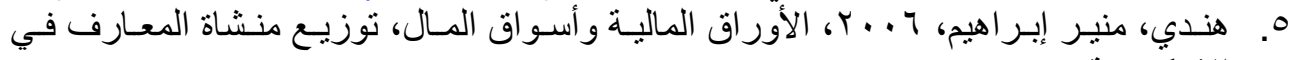
الإسكندرية، مصر ملير إير اهئ
}

\section{ثانياً. المراجع باللغة الاجنبية}

1. Ahmad Ramly ,2004," Money and Capital Market Financial Intermediaries Role and Functions"(www.mgv.mim.edu.my/mmr/8104/810405.htm- 38k).

2. Alfaro Laura, CHanda Areendam, Ozcan Kalemli and Sayek Selin,2002"FDI Spillovers, Financial Market and growth".(www.people.hbs.edu/lalfaro/ papers/fdispil/overs).

3. Andritzky.R Jochen ,2007"Capital Market Development In a Small country of Slovenia"(www.imf.org/external/pubs/ft/wp/2007/wpo7229.pdf) 
4. Cetorelli Nicola and Gambera Michele,1999"Banking Market Structure, Financial Dependence and Growth: International Evidence From industry Data"(www.chicagofed.org/publication/workingpapers/paper Wp99_8pdf.).

5. Eatwell John and Taylor Lance,1998 "International Capital Markets and the Future of Economic Policy" (www.newschool.edu/cepa).

6. Fecht Falko, Hung Kevin and Martin Antoine,2005"FinancialIntermediaries, Markets and Growth". $\quad$ (www.bundesbank.de/download/volswirtschaft/ dkp/2005/200503dkp.pdp.).

7. Hussein.A Khaled,"Finance and growth in Egypt". (www.iceg.org/ne/ Projects/ Financial /growth.pdf.), 1999.

8. Levine Ross,2004 "Finance and Growth: Theory and Evidence", (Econ.brown.edu/fac/forthcoming/forth_Book_Durlauf_finngrowth_pdf.).

9. Ray Tridip,2002" Financial Development and Economic Growth: A revie Of Literature". (www.isid.ac.in/planning /slides-isi -litreview.pdf.)

10. Rousseau L.Peter and Wachtel Paul,2005"Economic Growth and Financial Depth: Is The Relationship Extinct Already?" (www.stern.nyu.edu/ Eco/wkpapers/wider.pdf.),

11. Sansui Nur,Fuad Nick and Abu Hasan Fauziah,2003"Strategiesfor Economic Growth: The role of financial depth".(subs.montclair.edu/cib/conference/cd/ Section2.pdf.).

12. Townsend Robert and Ueda Kenichi 2003,"Financial Deeping, Inequality, and Growth: Model-Based Quantitative Evaluation". (Cier.uchicago.edu/papers/ueda/uedatownsend.pdf.). 